\title{
Experimental Study on Hydrogen Leakage and Emission of Fuel Cell Vehicles in Confined Spaces
}

\author{
Dong Hao ${ }^{1} \cdot$ Xiaobing Wang ${ }^{1} \cdot$ Yanyi Zhang ${ }^{1} \cdot$ Renguang Wang ${ }^{1} \cdot$ Guang Chen ${ }^{1} \cdot$ Jun $\mathrm{Li}^{1}$
}

Received: 29 July 2019 / Accepted: 31 October 2019 / Published online: 12 May 2020

(c) The Author(s) 2020

\begin{abstract}
Hydrogen safety is one of the most important safety indicators in fuel cell vehicles (FCVs) (unlike in other types of alternative energy vehicles). This indicator in FCVs is directly related to the user's personal safety in daily vehicle usage. This paper analyzes the safety standards of FCVs in confined spaces. A sealed test chamber and an appropriate test method are developed to evaluate vehicle safety based on specific test requirements. Two FCVs are subjected to static hydrogen leakage and hydrogen emission testing performed in a confined space. The results reveal that the hydrogen concentration in the vicinity of the vehicles approximates $0.0004 \%$ which is much lower than $1 \%$ while parked for $8 \mathrm{~h}$ during the hydrogen leakage test. In the hydrogen emission test under operating conditions, the concentration of the hydrogen gas emitted from the vehicles exceeds $2300 \mathrm{ppm}$ in the vicinity, which requires careful consideration. Based on experiment and analysis, recommendations for the hydrogen safety standards of FCVs in confined spaces are proposed.
\end{abstract}

Keywords Fuel cell vehicle · Hydrogen safety · Confined spaces · Garage

Abbreviations
$\begin{array}{ll}\text { ACH } & \text { Air change per hour } \\ \text { CFD } & \text { Computational fluid dynamics } \\ \text { CNS } & \text { Chinese National Standards } \\ \text { FCV } & \text { Fuel cell vehicle } \\ \text { GTR } & \text { Global Technical Regulation } \\ \text { NWP } & \text { Nominal working pressure }\end{array}$

\section{Introduction}

Fuel cell vehicles (FCVs) are considered to be an important alternative to fossil fuel-based vehicles, potentially enabling sustainable growth of the automotive industry. They represent an ideal solution to climate change and the global energy crisis due to their zero emissions, high efficiency, and the diversified sources of hydrogen available. In recent decades, governments and major automobile groups have attached great importance to the research and development of FCV-related technologies. Considerable resources are invested in FCVs and hydrogen energy technologies

Dong Hao

haodong@catarc.ac.cn

1 China Automotive Technology and Research Center Co., Ltd., Tianjin 300300, China research and development, test validation, and market cultivation [1]. Importantly, the fuel source is hydrogen, which is an extremely light and flammable gas [2]. Hydrogen is the lightest of all the gases with a density of $1 / 14$ of that of air. Under standard atmospheric pressure and $0{ }^{\circ} \mathrm{C}$, the density of hydrogen is approximately $0.0899 \mathrm{~g} / \mathrm{L}$. It diffuses easily in air and has a high tendency to leak, which makes it difficult to be contained. Hydrogen has a wide flammability range from 4 to $75 \%$ and a very low ignition energy (approximately 10 times lower than that of classic hydrocarbons). In addition, the flame of hydrogen combustion in air is almost invisible and has a high temperature of more than $2000{ }^{\circ} \mathrm{C}$.

From the perspective of clean energy production, hydrogen appears to be the most suitable solution to overcoming the current energy and environmental crisis [3]. It is widely available in the form of water and can be extracted through solar, wind or other clean energy. Therefore, hydrogen energy and hydrogen FCVs are considered ideal. However, this point does not consider the risks during production, storage, transportation, and usage processes. In particular, during the design, development, manufacture, driving, parking, and post-crash of FCVs, there should be a direct focus on hydrogen safety.

Liu et al. [4] studied the dispersion of hydrogen around a hydrogen FCV after accidental leakage of the hydrogen. The models showed that a ground effect blower with the diffuser 
flushing to the floor more effectively removes most of the hydrogen to create a safety envelope around the vehicle. The effect of blower ventilation to disperse hydrogen leaking from a hydrogen fueled vehicle in an emergency was studied numerically with comparison with experimental data by Xie et al. [5]. Steady-state calculations showed that the blower significantly reduced the hydrogen concentrations around the vehicle with hydrogen concentrations in most areas below the lower flammability limit. The natural and forced mixing and dispersion of hydrogen released from a high-pressure tank into a partially enclosed compartment was investigated using analytical models by Prasad et al. [6]. Results indicated that forced ventilation was a viable technique for reducing hydrogen volume fraction in the compartment, and for reducing the time interval during which dangerous levels of hydrogen concentration existed in the compartment. In addition, Olvera et al. [7] analyzed the influence of buildings on hydrogen diffusion using the standard $k-\varepsilon$ turbulence model. They concluded that the hazard of indoor hydrogen release was more serious than that of indoor compressed natural gas release.

Although hydrogen is less likely to cause a fire or explosion hazard in an open or well-ventilated space (due to its tendency to easily diffuse), it can cause a safety risk if it accumulates in a confined or poorly ventilated space. Therefore, the safety of FCVs interior [8] and the related infrastructure, including hydrogen fueling station [9], tunnels, garages, parking, and maintenance workshops deserves special attention and further research.

Once the release (hydrogen leakage or emission) happens in a tunnel, the hydrogen will accumulate inside the tunnel and lead to great risk of deflagration and detonation [10]. Multiple numerical simulation studies have been performed concerning risk assessment of hydrogen releases in tunnels. Middha et al. [11] found that for hydrogen vehicles a typical worst-case risk assessment approach assuming the full gas inventory being mixed homogeneously at stoichiometry could lead to severe explosion loads. Houf et al. [12] performed computational fluid dynamics (CFD) simulation for hydrogen releases from a hydrogen FCV in a full-scale tunnel. The results indicated that the level of potential risk from hydrogen vehicle accidents involving thermally activated pressure relief devices in tunnels did not appear to significantly increase the level of risk. Tolias et al. [13] also performed CFD simulations on hydrogen deflagration in a homogenous and near-stoichiometric hydrogen-air mixture in a model of a tunnel. The sensitivity investigation for the simulation parameter of the combustion model illustrated that even small changes can influence the simulation results. Bie et al. [14] studied the risk associated with hydrogen released from on-board high-pressure hydrogen vessels in subsea tunnels through simulation. The length, width, and height of the hydrogen leaking vehicle were $4700 \mathrm{~mm}$,
$1800 \mathrm{~mm}$ and $1500 \mathrm{~mm}$, respectively, according to a typical mid-sized vehicle. It was found that ventilation can greatly influence the distribution of hydrogen when hydrogen is released from the FCV. The upstream of the ventilation was less hazardous than the downstream and the risk around the hydrogen leaking vehicle was reduced significantly.

Similarly, a hydrogen FCV in a garage can also cause a safety hazard if a leakage or emission occurs that would result in an accumulation of a flammable hydrogen-air mixture within the garage or vehicle. Pitts et al. [15] studied the distribution of the hydrogen fraction in the garage with and without a vehicle. A garage with interior dimensions of $6100 \mathrm{~mm}$ (width) $\times 6100 \mathrm{~mm}$ (length) $\times 3050 \mathrm{~mm}$ (height) was constructed. Several tests were run in which conventional automobiles were parked in the garage centered over the hydrogen release position. The hydrogen was released by a simulated device. Hydrogen-air mixtures were ignited for volume percentages between $6 \%$ and 29\%. Garage and vehicle damaged due to hydrogen burning were qualitatively characterized. This work simulated a scenario that a FCV discharged large amounts of hydrogen accidentally in a garage and presented valuable conclusions. Merilo et al. [16] performed a series of experiments to investigate hydrogen release accidents in a vehicle garage. The internal dimensions of the garage facility measured $2720 \mathrm{~mm}$ high, $3640 \mathrm{~mm}$ wide, and $6100 \mathrm{~mm}$ long. Tests were performed with hydrogen release rates of $1.6 \mathrm{~kg} / \mathrm{h}$, $3.3 \mathrm{~kg} / \mathrm{h}, 4.9 \mathrm{~kg} / \mathrm{h}$, and $6.7 \mathrm{~kg} / \mathrm{h}$ and ventilation rates of $0.1 \mathrm{~m}^{3} / \mathrm{s}, 0.2 \mathrm{~m}^{3} / \mathrm{s}$, and $0.4 \mathrm{~m}^{3} / \mathrm{s}$. The maximum concentration and overpressure obtained in the mechanical ventilation test configuration were produced with a $6.7 \mathrm{~kg} / \mathrm{h}$ release and a ventilation rate of $0.1 \mathrm{~m}^{3} / \mathrm{s}$. It is meant that the worst situation occurred with a $6.7 \mathrm{~kg} / \mathrm{h}$ hydrogen release and a ventilation rate of 6 air exchange per hour (ACH). Hajji et al. [2] studied the dispersion of hydrogen in a prismatic garage using the software and considering important factors such as the leak position, leak duration, and the mass flow rate that influence the behavior of the hydrogen concentration and accumulation. The simulation results showed that when the source was approaching the center of the garage (which was the optimum position), velocity profiles were symmetrical and there was encouragement of stable stratification. The variation of mass flow rate and the duration of the leak of hydrogen played a crucial role in determining risk. Leakage time was important in determining hydrogen concentration when the mass flow rate was low. A parametric study was carried out by Molkov et al. [17] to formulate acceptable numerical and physical requirements from the hydrogen safety engineering perspective. Simulations of a light gas release and dispersion in an enclosure with one vent were performed. Koutsourakis 
et al. [18] studied the hydrogen release and accumulation within a non-ventilated ambient pressure garage using CFD. Choi et al. [19] analyzed safety issues in an underground parking garage when hydrogen leaks from a FCV by CFD simulations. Venetsanos et al. [20] predicted the short- and long-term mixing and distribution of hydrogen releases in confined spaces using various CFD tools and modeling approaches. Giannissi et al. [21] studied hydrogen distribution inside a single-vented facility exposed to wind using CFD. Papanikolaou et al. [22] investigated the ventilation requirements for parking hydrogen-fueled vehicles in residential garages using numerical analysis and experiments with helium. However, elaborate experimental information was required to validate the different CFD approaches for these studies. Moreover, Tolias et al. [23] and Baraldi et al. [24] have made lots of efforts to improve the hydrogen safety assessment technology using CFD.

Adams et al. [25] estimated an allowable hydrogen permeation rate for automotive legal requirements and standards. For a test conducted on new hydrogen containers at a temperature of $20^{\circ} \mathrm{C}$, the estimated maximum allowable permeation rate was $8.0 \mathrm{~mL} / \mathrm{h} / \mathrm{L}$ water capacity. That is to say, for a FCV equipped with two hydrogen containers of $120 \mathrm{~L}$ water capacity, the allowable hydrogen permeation rate was $16 \mathrm{~mL} / \mathrm{min}$. This conclusion was useful for studying the hydrogen leakage performance of FCV. However, the allowable hydrogen leakage from the highpressure valve, pipelines, and joints were not presented. Brennan et al. [26] suggested that regulation, codes, and standards of safety assessment on hydrogen discharge in garage should be investigated.

In summary, experimental investigation and standardization research of hydrogen safety of FCVs in confined spaces using hydrogen are still limited in the available literature to date. First, the standards and regulations related to hydrogen safety of FCVs in confined spaces are reviewed in this work. Next, a sealed test chamber for the evaluation of hydrogen safety of FCVs is designed and developed. In addition, the control system of the chamber is developed according to the test requirements. Detailed test methods for hydrogen leakage of a static vehicle and hydrogen emission during operation are then established. Finally, the test methods are evaluated using two fuel cell passenger cars. Generally, compared with other studies, there are two main purposes of this work. Firstly, references and recommendations are proposed for the development of FCV hydrogen safety standards based on experimental research. Second, the state of art of FCV hydrogen safety in single garage is presented in this work.

\section{Analysis of Existing Standards}

To ensure hydrogen safety in the usage of FCVs, four main measures are generally adopted and emphasized in related standards:

(1) Enforcement of strict requirements in all aspects of the design, production, and assembly of onboard hydrogen systems (including hydrogen storage vessels, hydrogen storage vessel valves, hydrogen pipelines, etc.) to prevent defects that may cause hydrogen leakage.

(2) A hydrogen concentration monitoring function, hydrogen leakage alarm function, and hydrogen cut-off function should be included in the design of the vehicle's hydrogen safety management system as a bare minimum.

(3) Enclosed or semi-enclosed spaces that may contribute to the accumulation of hydrogen should be avoided in the design of the vehicle body structure.

(4) In the design and development of fuel cell engines, a hydrogen recycling pump and an efficient control strategy should be employed to reduce the amount of hydrogen emitted from a FCV during idling or operation.

In response to these four measures, several international standards and regulations have established clear test assessment methods and safety requirements. For example, the Global Technical Regulations (GTRs) outline specific test methods and requirements for the safety of hydrogen storage containers. The Chinese National Standards (CNS) and Society of Automotive Engineers (SAE) stipulated test equipment requirements, test methods, and data processing methods for hydrogen emission of FCVs in an open space. However, for hydrogen safety of FCVs in confined spaces, GTR, SAE's Technical Standards, CNS, and other standard regulations only provided general recommendations and safety requirements without specifying requirements for test equipment and test methods.

Considering the present status of hydrogen safety of FCVs in confined spaces, each standard mainly focused on two aspects: a hydrogen leakage requirement of the vehicle under static conditions and a hydrogen emission requirement of the vehicle under operating conditions. The hydrogen leakage requirement under static conditions was primarily relevant to hydrogen safety when the vehicle was parked for long periods in a garage or other poorly ventilated space. In the case of the hydrogen emission requirement for operating conditions, the emphasis is on hydrogen safety during vehicle start-up, idling, or shutdown process in a garage or other mechanically ventilated space.

In GTRs, hydrogen safety of FCVs in garages was repeatedly highlighted and the corresponding safety 
requirements were specified. The SAE's Technical Standards introduced the technical problems that should be carefully considered in hydrogen safety tests of FCVs in confined spaces. CNS proposed the requirements for hydrogen leakage of FCVs in a closed space. However, the corresponding test methods were not outlined. This section compares and analyzes these three standards on hydrogen safety in confined spaces. It is concluded that further improvements in these test methods are required.

\subsection{Comparison of the Three Standards}

A comparison of the three international standards for hydrogen safety is listed in Table 1.

The ambient temperature required by GTR 13 was $55^{\circ} \mathrm{C}$. The vehicle's hydrogen storage container was filled to $115 \%$ NWP and the vehicle was parked in an enclosed and mechanically ventilated space. The hydrogen leaked from the vehicle must not cause an accumulation of the volume concentration of hydrogen in the surrounding space in excess of $1 \%$.

SAE J2578-2014 considered the absence or presence of mechanical ventilation in confined spaces. In its absence, unlike GTR, the test temperature required by SAE was normal temperature $\left(25 \pm 5^{\circ} \mathrm{C}\right)$ and the onboard hydrogen storage container was filled to the maximum design pressure. With mechanical ventilation, the operating conditions of the vehicle were specified (idle speed, start-up, and downtime). Similarly, SAE also required that the hydrogen leaked or emitted by the vehicle should not lead to the volume concentration of hydrogen in the surrounding space exceeding $1 \%$.

In CNS GB/T 26990-2011, the primary consideration was that under normal temperature conditions the vehicle was filled to $100 \%$ nominal working pressure (NWP) and the hydrogen leakage rate in the confined space should not exceed $0.15 \mathrm{NL} / \mathrm{min}$. The volume concentration of hydrogen in the space around the vehicle was not given.

By comparing the three criteria, it was determined that:

(1) In terms of test ambient temperature, GTR was the most stringent, reaching a high temperature of $55^{\circ} \mathrm{C}$. This simulates a vehicle parked in an unventilated garage on a hot summer day.

(2) In terms of vehicle filling pressure, SAE requirements were the most stringent and considered the maximum design pressure of hydrogen storage vessels. The most severe hydrogen leaks can be measured under such pressure conditions.

(3) In terms of test conditions, SAE provided the most comprehensive recommendations and included the various operating conditions that may occur in the garage, which most closely approximated an actual usage.

(4) In terms of safety requirements, both GTR and SAE stipulated that the volume concentration of hydrogen in the vicinity of the vehicle must not exceed $1 \%$, while GB/T only specified the hydrogen leakage rate.

\subsection{Analysis of the Test Methods to be Improved}

\subsubsection{Test Equipment Requirements}

For a confined space, both GTR and SAE specified internal dimensions as well as the air exchange rates. However, no specific explanation was given for the position and precision of the internal hydrogen concentration sensor, the physical construction, the location of the mechanical ventilation device, and the safety requirements of the confined space itself.

Table 1 Comparison of hydrogen safety-related standards for FCVs in confined spaces

\begin{tabular}{|c|c|c|c|}
\hline Standards & GTR13 & SAE J2578-2014 & CNS GB/T 26990-2011 \\
\hline Ambient ventilation & Airtight, no ventilation & $\begin{array}{l}\text { (a) Airtight, no ventilation } \\
\text { (b) Mechanical ventilation }\end{array}$ & Airtight, no ventilation \\
\hline Test environment temperature & $55^{\circ} \mathrm{C}$ & Normal temperature & Normal temperature \\
\hline Hydrogen storage vessel pressure & $\begin{array}{l}115 \% \text { nominal working } \\
\text { pressure (NWP) }\end{array}$ & Maximum design pressure & NWP \\
\hline Test conditions & Vehicle is parked & $\begin{array}{l}\text { (a) Parking } \\
\text { (b) Idling } \\
\text { (c) Start-up } \\
\text { (d) Shutdown }\end{array}$ & Vehicle is parked \\
\hline Hydrogen concentration around the vehicle & $\leq 1 \%$ & $\leq 1 \%$ & $\begin{array}{l}\text { No requirement of concentration. } \\
\text { Leakage rate less than } 0.15 \mathrm{NL} / \\
\text { min }\end{array}$ \\
\hline Test method & Not specified & Not specified & Not specified \\
\hline
\end{tabular}




\subsubsection{Vehicle Condition Requirements}

The requirements for the filling pressure of hydrogen storage vessels were stipulated in GTR and SAE, which were $115 \%$ NWP and the maximum design pressure, respectively. However, no specific requirements were imposed on the temperature of the vehicle before the start of the test (including the temperature of the hydrogen storage container). Inconsistent temperatures would result in the poor repeatability of the tests.

\subsubsection{Test Conditions}

In the three standards, the test conditions were the same for the hydrogen leak test for a vehicle under static conditions. However, the test conditions were not clearly defined for the hydrogen emission test for vehicles under operating conditions. In a confined space with mechanical ventilation, the hydrogen emission characteristics of a vehicle during startup, idle, and downtime process were different. Therefore, the design of a reasonable set of test conditions to comprehensively evaluate the safety of hydrogen emissions in a confined space was one of the research objectives of this investigation. The development of unified test conditions for a combined test was also one of the necessary requirements for the testing and evaluation of the performance of different vehicles.

\subsubsection{Test Duration Requirements}

GTR and SAE did not specify or recommend test durations for vehicle hydrogen leak tests and hydrogen emission tests in confined spaces. Therefore, one of the goals of this study was to determine a reasonable test duration to fully represent the hydrogen safety performance of the vehicle in a confined space.

\section{Hydrogen Safety Experiment}

\subsection{Sealed Test Chamber Development}

Based on extensive research, it was determined that there was no dedicated test equipment that satisfied the experimental requirements of this investigation. This limited the scope of research on hydrogen safety of FCVs in confined spaces. Therefore, this investigation initially involved a demand analysis, hardware and software design, and safety design of the test equipment. Finally, a sealed test chamber was developed for testing FCV hydrogen safety that satisfied the requirements of the experimental research, such as internal dimensions, security measures, and air exchange rate simulation.
Table 2 List of dimensions of fuel cell passenger cars on the market

\begin{tabular}{llll}
\hline Vehicle & Length $(\mathrm{mm})$ & Width $(\mathrm{mm})$ & Height $(\mathrm{mm})$ \\
\hline TOYOTA Mirai & 4890 & 1815 & 1535 \\
HONDA FCX Clarity & 4834 & 1847 & 1468 \\
HYUNDAI Nexo & 4671 & 1859 & 1631 \\
$\quad$ MercedesBenzGLCF- & 4734 & 1890 & 1603 \\
$\quad$ cell & & & \\
SAIC Roewe & 4996 & 1857 & 1507 \\
\hline
\end{tabular}

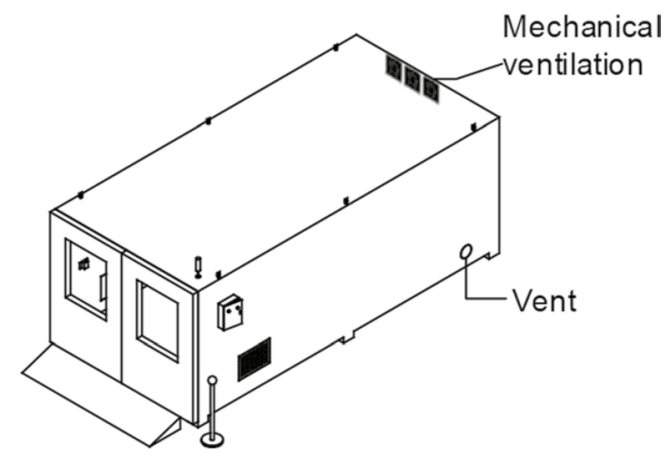

Fig. 1 Sealed test chamber designed for FCV hydrogen safety test

\subsubsection{Internal Dimensions}

The internal dimensions of confined spaces recommended in this paper are derived from GTR [27] and SAE [28] standards. In order to strictly evaluate the impact of the hydrogen released by the vehicle on the surrounding environment, the internal dimensions of the recommended confined space should not exceed the length, width, and height of the vehicle by $1000 \mathrm{~mm}, 1000 \mathrm{~mm}$, and $500 \mathrm{~mm}$, respectively. This report investigated the dimensions of fuel cell passenger cars currently on the market, as given in Table 2 . Considering the sizes of them, the internal dimensions of the sealed test chamber developed in this investigation were $5650 \times 2600 \times 1950 \mathrm{~mm}$ (length, width, and height). The inner height and outer height of the garage is $1950 \mathrm{~mm}$ and $2200 \mathrm{~mm}$, respectively. The internal volume of the chamber is $28.6455 \mathrm{~m}^{3}$. The design of the chamber is shown in Fig. 1 .

\subsubsection{Air Exchange Rate Simulation}

According to the studies of Adams et al. [25] and SAE $\mathrm{J} 2578$ [28], a value of $0.03 \mathrm{ACH}$ was the lowest measured value and representative of a worst-case scenario in garage. It represented an extremely "tight" wood frame structures (with plastic vapor barriers, weather-stripping on the doors, and no vents) that were sheltered from wind and underwent no significant daily temperature swings to cause densitydriven infiltration. For the test chamber in this paper, when 
all the mechanical ventilation and vents were closed, the air exchange rate was no more than $0.03 \mathrm{ACH}$. When two fans and two vents were opened, the air exchange rate was $6 \mathrm{ACH}$, which was taken for hydrogen emission test. When all the mechanical ventilation and vents were opened, the air exchange rate reached the maximum value of $9 \mathrm{ACH}$, which was used for the emergency ventilation.

In this work, two levels of air exchange rate were adopted:

(1) To simulate the long-term parking state of the vehicle in an enclosed garage, the minimum air exchange rate of the test chamber was no more than $0.03 \mathrm{ACH}$. In this scenario, a hydrogen leak test of the vehicle was performed in the parked state.

(2) To simulate a scenario whereby the vehicle was operating for a short period of time in a mechanically ventilated garage, the test chamber had the capability to simulate a $6 \mathrm{ACH}$ air exchange rate. In this scenario, hydrogen emission testing was performed on a vehicle under operating conditions.

\subsubsection{Security Measures}

The risks associated with hydrogen in confined spaces were much higher than that in open spaces. As such, the safety design of the sealed chamber was particularly important.

In terms of passive protection, the test chamber had a complete explosion-proof design including explosion-proof lamps, fans, cables, and other components to avoid risks (such as electric sparks). The entire test chamber was also grounded for fast and effective elimination of static electricity. With respect to active protection, the hydrogen concentration sensor monitored the hydrogen concentration level in the test chamber throughout the process. In the event of an excessively high hydrogen concentration, the test chamber emitted an audible and visual alarm and automatically activated the emergency ventilation function to quickly discharge the hydrogen in the cabin to avoid safety risks.

\subsubsection{Arrangement of Key Components}

Hydrogen has a low density and therefore tends to easily drift upwards. Therefore, to measure the highest value of hydrogen concentration in the sealed chamber, a hydrogen sensor was arranged at each of the four corners of the inner surface of the enclosed compartment, as shown in Fig. 2. The height of all hydrogen sensors from the chamber ground was approximately $1920 \mathrm{~mm}$. The hydrogen concentration sensor had a range of $0-10,000 \mathrm{ppm}$ and a resolution of $1 \mathrm{ppm}$. Using the self-developed data acquisition system, a sampling frequency of $1 \mathrm{~Hz}$ was realized.

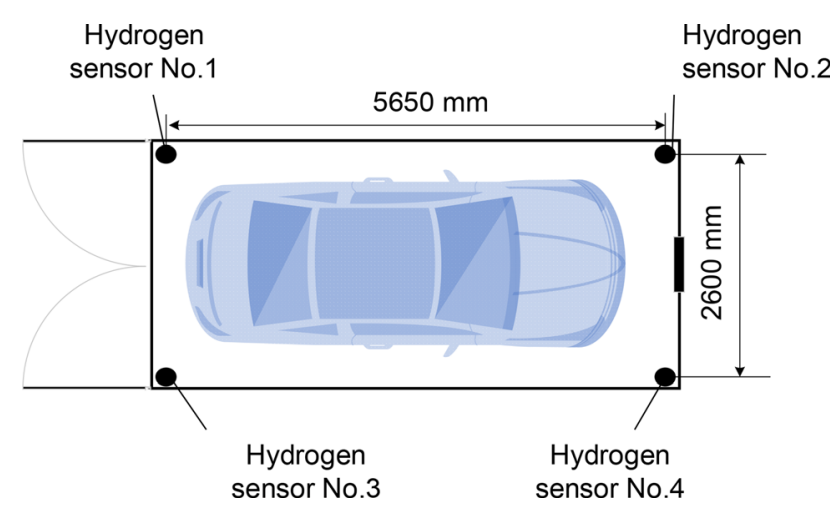

Fig. 2 Schematic diagram of the position of the hydrogen concentration sensor as viewed from the top of the test chamber

To satisfy the requirements for air exchange rate simulation and emergency ventilation, mechanical ventilations were installed on the chamber wall opposite the door. Three fans with same performance parameters were installed near the ceiling, as shown in Fig. 1. The dimensions of the fan were $120 \times 120 \times 38 \mathrm{~mm}$ (length, width, and thickness). The fan diameter was $100 \mathrm{~mm}$. The air velocity of the fan was $86.0 \mathrm{~m}^{3} / \mathrm{h}$ at the speed of $1600 \mathrm{rpm}$. At the position near the floor, two circular vents with diameter of $100 \mathrm{~mm}$ were installed. When all the fans and vents were closed, the air exchange rate of the test chamber was no more than $0.03 \mathrm{ACH}$. When two fans and two vents were opened, the air exchange rate of the test chamber was $6 \mathrm{ACH}$. In this work, the test chamber was placed in a laboratory maintained at a temperature of $25 \pm 5^{\circ} \mathrm{C}$ to meet the test temperature conditions. In future research, in order to consider the effect of temperature on FCV hydrogen leakage and emission, the temperature control and acquisition functions of the test chamber will be improved.

The sealed test chamber that was developed to evaluate hydrogen safety of FCVs is shown in Fig. 3.

\subsection{Test Method}

The frequently occurring scenarios of FCVs in garages included long-term parking and short-term operations. For these two scenarios, the experimental design of this investigation was divided into two parts:

(1) Hydrogen leak test in a confined space without mechanical ventilation.

(2) Hydrogen emission test in a confined space with mechanical ventilation (air exchange rate of $6 \mathrm{ACH}$ ). 


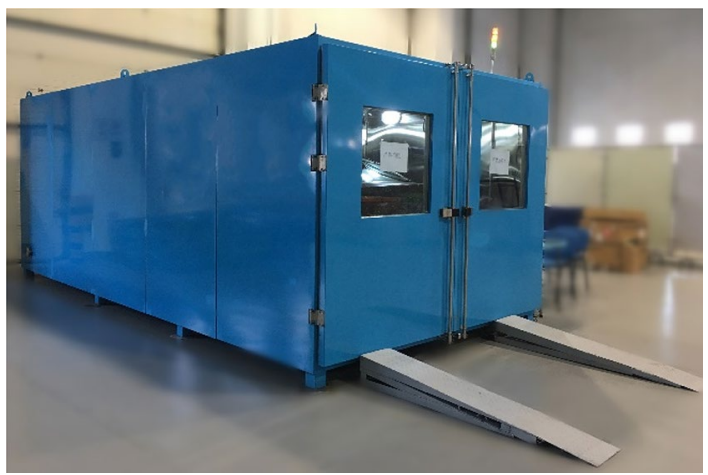

Fig. 3 Sealed test chamber for the evaluation of hydrogen safety of FCVs

\subsubsection{Hydrogen Leak Test Under Parking Condition}

This test was conducted to verify the hydrogen leakage of a vehicle in a confined space without mechanical ventilation. During the vehicle preparation phase, the hydrogen storage vessel was filled to the NWP. Before the hydrogen leak test, the vehicle first completed the entire process including start-up, purge, idling and shutdown outside of the sealed chamber. The purpose of this process was to confirm that the vehicle was in a fault-free state to ensure the follow-up test could be conducted normally. The vehicle was then placed in a confined space, shutdown, and with the ambient temperature set at $25 \pm 5^{\circ} \mathrm{C}$ for $12 \mathrm{~h}$ to ensure that the hydrogen in the vehicle and the hydrogen storage container was consistently at the ambient temperature. After this process was completed, the hydrogen concentration in the environment and the test chamber were measured. When the hydrogen concentration was 0 , the door of the test chamber was closed and data were acquired by hydrogen sensors. The test lasted $8 \mathrm{~h}$ and the sampling frequency was $1 \mathrm{~Hz}$.

When the vehicle was shut off in a confined space, the hydrogen supply shutoff valve was closed, and the total discharge from the onboard hydrogen system due to leakage, permeation, and venting (if any) became the dominant source for hydrogen introduced to the enclosure. However, it is difficult to obtain the total leakage rate (including hydrogen permeation through hydrogen storage vessels, hydrogen leakage in the high-pressure valve, and hydrogen leakage in pipelines and joints) through experiments conducted on a whole vehicle. Therefore, the actual value of hydrogen concentration in $8 \mathrm{~h}$ was adopted as a safety parameter to evaluate the influence of hydrogen leakage on vehicle's surrounding environment.

\subsubsection{Hydrogen Emission Test Under Combined Operating Conditions}

This test was conducted to determine the influence of hydrogen emitted from the vehicle during start-up, idling, and shutdown in a confined space with mechanical ventilation. The vehicle preparation and immersion process were consistent with the steps in Sect. 3.2.1. The mechanical ventilation was opened at the beginning of the experiment with 6 $\mathrm{ACH}$. After closing the door of the test chamber, the vehicle was started and the fuel cell engine was kept idle for at least $10 \mathrm{~min}$ before being subsequently shutdown. Hydrogen concentration sensor data were acquired from the start-up of the vehicle and the acquisition process was terminated when the hydrogen concentration at each position in the test chamber showed a significant decline after shutdown. The total duration of the test was related to the time taken for the shutdown process (with a sampling frequency of $1 \mathrm{~Hz}$ ).

\subsection{Test Vehicles}

In this investigation, two fuel cell passenger cars were subjected to hydrogen leakage and hydrogen emission tests. The dimensions of the vehicles were approximately $5000 \times 1800 \times 1500 \mathrm{~mm}$ (length, width, and height), which met the dimensional requirements.

Both the onboard hydrogen storage systems included two hydrogen storage tanks with a nominal working pressure of $70 \mathrm{MPa}$ that were both mounted under the rear seats and the trunk of the vehicle. The difference was that vehicle A was equipped with Type IV hydrogen tanks, while vehicle B was equipped with Type III hydrogen storage tanks.

For road vehicle applications, compressed gaseous hydrogen systems typically have a maximum storage pressure of 35 or $70 \mathrm{MPa}$ and are designed to operate within normal ambient temperature ranges. In legal requirements and standards, compressed gas hydrogen containers are normally categorized into the following four types: Type-I, Type-II, Type-III, and Type-IV. Type-III means fully wrapped container with a seamless or welded metallic liner; Type-IV means fully wrapped container with a non-metallic liner; the main difference between Type-III and Type-IV tank is the material of the liner.

\section{Results and Discussion}

\subsection{Hydrogen Leakage in the Parked State}

Hydrogen leakage of the two vehicles in the parked state are shown in Figs. 4 and 5. The test results indicate that the two vehicles had different degrees of hydrogen leakage. After vehicle $A$ and vehicle $B$ were parked for $0.2 \mathrm{~h}$ and $0.5 \mathrm{~h}$, respectively, hydrogen gas was detected in the sealed chamber. With the progression of time, the hydrogen concentration showed a nearly linear upward trend. After parking for $8 \mathrm{~h}$, the hydrogen leakage of vehicle A and vehicle B resulted in the detection of the highest hydrogen concentration in the 


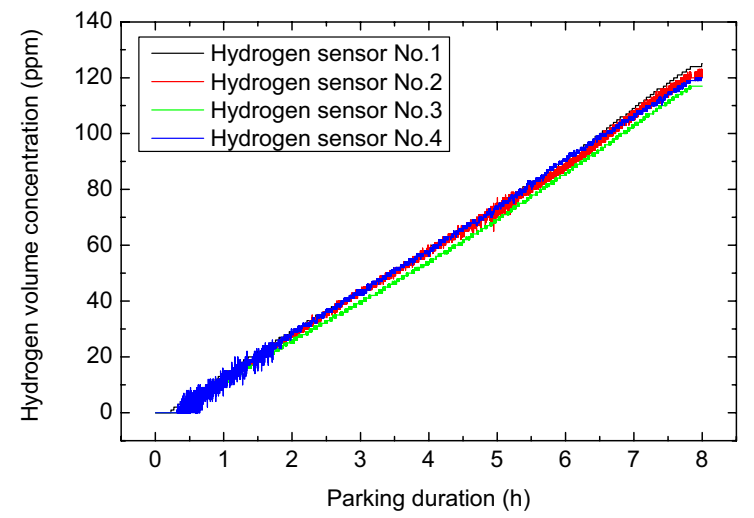

Fig. 4 Hydrogen concentration curve for the parked state (vehicle A)

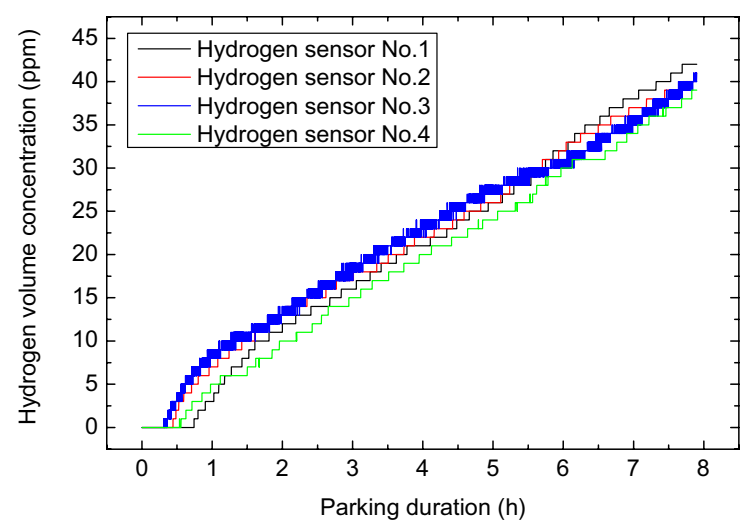

Fig. 5 Hydrogen concentration curve for the parked state (vehicle B)

chamber at $125 \mathrm{ppm}$ and $42 \mathrm{ppm}$, respectively (as given in Table 3). Vehicle B had a lower hydrogen leakage rate compared to vehicle A. However, the test results for both vehicles were much smaller than the safety limit of $10,000 \mathrm{ppm}$ required by the GTR and SAE standards.

Additionally, after hydrogen gas was detected in the sealed chamber, the hydrogen concentration raised at a nearly constant rate. Therefore, the test period in this investigation was $8 \mathrm{~h}$, which was enough to examine the hydrogen leakage of the vehicle without the need to further increase the test duration. For another reason, the test duration of $8 \mathrm{~h}$ could simulate the daily use of most vehicles, that is, the scene where the vehicle was parked overnight in the garage. Considering the No. 1 position in the test with vehicle $\mathrm{B}$ as an example, if the hydrogen concentration raised at the measured rate (approximately $5.544 \mathrm{ppm} / \mathrm{h}$ ), it required approximately $1800 \mathrm{~h}$ to reach the safety limit of $10,000 \mathrm{ppm}$.

According to the test results, hydrogen leaks were detected in both FCVs in this investigation. The main sources of leakage included hydrogen permeation through hydrogen storage vessels, hydrogen leakage in the high-pressure valve, and hydrogen leakage in pipelines and joints. Although the amount of leakage measured in this investigation was low, hydrogen leakage of vehicles should attract more attention from researchers to ensure the safety of users in the "enclosed garage $+\mathrm{FCV}$ " scenario.

In this experiment, the internal volume of the confined space minus the material volume of the vehicle is $V_{\text {Room }}(\mathrm{L})$. At test time $t$, the rate of gas entering chamber $G_{\mathrm{g}}(\mathrm{L} / \mathrm{min})$ is the sum of the hydrogen leakage rate $Q_{\mathrm{H}_{2}}(\mathrm{~L} / \mathrm{min})$ and the fresh air rate $Q_{\text {air }}(\mathrm{L} / \mathrm{min})$. In that case, the hydrogen concentration of the gas entering chamber can be expressed by the following equation:

$G_{\mathrm{H}_{2}}=\frac{Q_{\mathrm{H}_{2}}}{Q_{\mathrm{H}_{2}}+Q_{\text {air }}}$

After test duration $\Delta t$, the volume of gas entering the chamber is:

$G_{\mathrm{g}}=\left(Q_{\mathrm{H}_{2}}+Q_{\text {air }}\right) \Delta t$

The hydrogen concentration in the chamber is $C_{\mathrm{H}_{2}}$. The variation of $C_{\mathrm{H}_{2}}$ can be expressed by the following equation:

$G_{\mathrm{g}} G_{\mathrm{H}_{2}}+\left(V_{\mathrm{Room}}-G_{\mathrm{g}} \Delta t\right) C_{\mathrm{H}_{2}}=V_{\mathrm{Room}}\left(C_{\mathrm{H}_{2}}+\Delta C_{\mathrm{H}_{2}}\right)$

Combined Eqs. (1), (2) and (3):

$$
\begin{aligned}
& \frac{Q_{\mathrm{H}_{2}}}{Q_{\mathrm{H}_{2}}+Q_{\text {air }}}\left(Q_{\mathrm{H}_{2}}+Q_{\text {air }}\right) \mathrm{d} t+\left[V_{\text {Room }}-\left(Q_{\mathrm{H}_{2}}+Q_{\text {air }}\right) \mathrm{d} t\right] C_{\mathrm{H}_{2}} \\
& =V_{\mathrm{Room}}\left(C_{\mathrm{H}_{2}}+\mathrm{d} C_{\mathrm{H}_{2}}\right)
\end{aligned}
$$

As a consequence, the hydrogen concentration in the chamber, $C_{\mathrm{H}_{2}}$, can be derived:
Table 3 Maximum hydrogen concentration of sealed chamber with a vehicle in the parked state

\begin{tabular}{llll}
\hline $\begin{array}{l}\text { Hydrogen sensor } \\
\text { No. }\end{array}$ & Sensor location & $\begin{array}{l}\text { Vehicle A maximum concen- } \\
\text { tration }(\mathrm{ppm})\end{array}$ & $\begin{array}{l}\text { Vehicle B maximum } \\
\text { concentration }(\mathrm{ppm})\end{array}$ \\
\hline 1 & Left rear of vehicle & 125 & 42 \\
2 & Left front of vehicle & 122 & 41 \\
3 & Right rear of vehicle & 117 & 41 \\
4 & Right front of vehicle & 120 & 39 \\
\hline
\end{tabular}


$C_{\mathrm{H}_{2}}(t)=\frac{Q_{\mathrm{H}_{2}}}{Q_{\mathrm{H}_{2}}+Q_{\text {air }}}-\frac{Q_{\mathrm{H}_{2}}}{Q_{\mathrm{H}_{2}}+Q_{\text {air }}} \mathrm{e}^{-\left(\frac{Q_{\mathrm{H}_{2}+Q_{\text {air }}}}{V_{\mathrm{Room}}}\right) t}$

where the air flow in/out of the confined space is $Q_{\text {air }}$ in $\mathrm{L} /$ min:

$Q_{\text {air }}=\frac{R_{\text {air }} \times V_{\text {Room }}}{60}$

where $C_{\mathrm{H}_{2}}(t)$ is the time-dependent hydrogen concentration in the confined space; $Q_{\mathrm{H}_{2}}$ is the total hydrogen discharge rate from the vehicle in $\mathrm{L} / \mathrm{min} ; R_{\text {air }}$ is the air exchange rate of the confined space in $\mathrm{ACH} ; V_{\mathrm{Room}}$ is the volume of the confined space minus the material volume of the vehicle in L. As mentioned above, the total hydrogen discharge from vehicle was mainly due to the hydrogen permeation through hydrogen storage vessels and hydrogen leakage from the high-pressure valve, pipelines, and joints.

Combined with the test results of vehicle A, assuming an even distribution of hydrogen in the chamber, the average hydrogen concentration was $121.00 \mathrm{ppm}$. According to Eqs. (5) and (6), the total hydrogen leakage rate $Q_{\mathrm{H}_{2}}$ of vehicle A could be calculated to be $6.43 \mathrm{~mL} / \mathrm{min}$. Similarly, for vehicle $\mathrm{B}$, the average hydrogen concentration in the chamber was $40.75 \mathrm{ppm}$, so the total hydrogen leakage rate of vehicle B was $2.14 \mathrm{~mL} / \mathrm{min}$. Based on the data provided by the manufacturers, the hydrogen permeation rates of the hydrogen storage vessels of vehicle A and B were approximately $2.35 \mathrm{~mL} / \mathrm{min}$ and $1.80 \mathrm{~mL} / \mathrm{min}$, respectively. Therefore, by applying this method, the hydrogen leakage characteristics of vehicles could be quantitatively evaluated, as given in Table 4. It could be found that the hydrogen leakage performance of vehicle B is significantly better than that of vehicle A. By removing the influence of different hydrogen permeability of the Type-III and Type-IV tank, the sealing of the high-pressure valves, pipelines, and joints of vehicle $\mathrm{B}$ was better than that of vehicle A.

\subsection{Hydrogen Emissions Under Combined Operating Conditions}

In this investigation, two vehicles were measured for hydrogen emissions under combined conditions and different characteristics were observed.
As shown in Fig. 6, after start-up, vehicle A entered the start-up purge process. Before the fuel cell engine started, in order to supply the hydrogen into the anode rapidly or purge the air in the anode which permeated from the cathode during parking condition, some hydrogen was supplied into the stack with pressure and then discharged from the tail pipe of the vehicle. This process was named as "start-up purge process." As a consequence, the hydrogen concentration at the No. 3 position near the vehicle exhaust outlet rapidly increased to $695 \mathrm{ppm}$. Subsequently, the hydrogen gas at position No. 3 diffused to other positions in the chamber and hydrogen gas was detected at positions No. 1, No.2, and No. 4 in turn. The fuel cell engine automatically maintained the idling state for $10 \mathrm{~min}$. During idling, the hydrogen concentration at each position in the chamber did not increase noticeably. Subsequently, the vehicle was again shutdown and the fuel cell engine automatically entered the "shutdown purge process." In order to decrease the water produced by electrochemical reaction and adjust the humidity inside the fuel cell stack, during the shutdown process of fuel cell engine, some hydrogen was supplied into the stack with pressure and then discharged from the tail pipe of the vehicle. As a consequence, this process rapidly raised the hydrogen concentration at the No. 3 position from 242 to $2356 \mathrm{ppm}$. Meanwhile, it caused the hydrogen concentration at other positions to increase significantly. Finally, under the action of mechanical ventilation, the hydrogen concentration in the chamber gradually decreased. During the test of

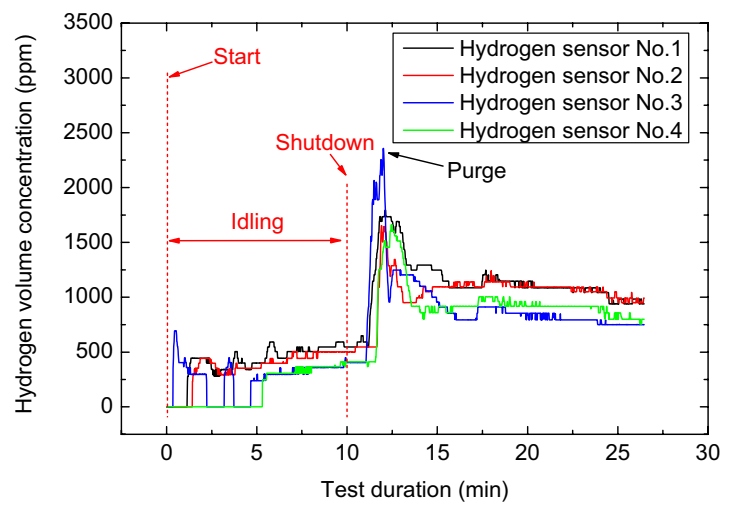

Fig. 6 In-chamber hydrogen concentration curve (vehicle A) under combined operating conditions
Table 4 The estimation of hydrogen leakage characteristics of vehicle $\mathrm{A}$ and $\mathrm{B}$

\begin{tabular}{lcc}
\hline & Vehicle A & Vehicle B \\
\hline Total hydrogen leakage rate (mL/min) & 6.43 & 2.14 \\
The rate of hydrogen permeation through storage vessels (mL/min) & 2.35 & 1.80 \\
The rate of hydrogen leakage from valves, pipelines, and joints (mL/min) & 4.08 & 0.34 \\
The percent of hydrogen from hydrogen vessels (\%) & 36.5 & 84.1 \\
The percent of hydrogen from valves, pipelines, and joints $(\%)$ & 63.5 & 15.9 \\
\hline
\end{tabular}


vehicle $\mathrm{A}$, the shutdown purge process caused the highest hydrogen concentration value to occur at the No. 3 position near the tail pipe.

As shown in Fig. 7, after start-up, vehicle B also entered the "start-up purge process" and discharged hydrogen from the tailpipe. As a consequence, the hydrogen concentration at the No. 1 position near the vehicle exhaust outlet rapidly increased to $232 \mathrm{ppm}$. Subsequently, the hydrogen gas at position No. 1 diffused to other positions in the chamber and hydrogen gas was successively detected at positions No. 2 to No. 4 . The vehicle's control strategy caused the fuel cell engine to automatically stop after the start-purge. Then, the engine restarted after 6 min and entered the idling state until the 16th minute. As a consequence, the total idle duration of the fuel cell engine was $10 \mathrm{~min}$. During idling, the hydrogen concentration at each position in the chamber did not increase significantly but remained essentially stabilized at approximately $75 \mathrm{ppm}$. At the 16th minute, the vehicle was again shutdown and the fuel cell engine automatically entered the shutdown purge process. This process slowly raised the hydrogen concentration in the chamber to $130 \mathrm{ppm}$ without exceeding the hydrogen concentration during the start-up purge. Subsequently, under the action of mechanical ventilation, the hydrogen concentration in the chamber gradually decreased. During the testing of vehicle $\mathrm{B}$, the start-up purge process caused the highest hydrogen concentration value to occur at the No. 1 position near the gas exhaust outlet.

At present, all the FCVs in the market adopted a hybrid technical solution of "fuel cell + battery." Under idling condition, the power generated by the fuel cell stack provided energy for auxiliary system or charged the battery of vehicle. When the energy storage in the battery was enough for the auxiliary system or the battery was with a high state of charge (SOC), the fuel cell engine maybe shutdown according to the control strategy. In this work, the battery capacity of vehicle B was much lower than that of vehicle A. That

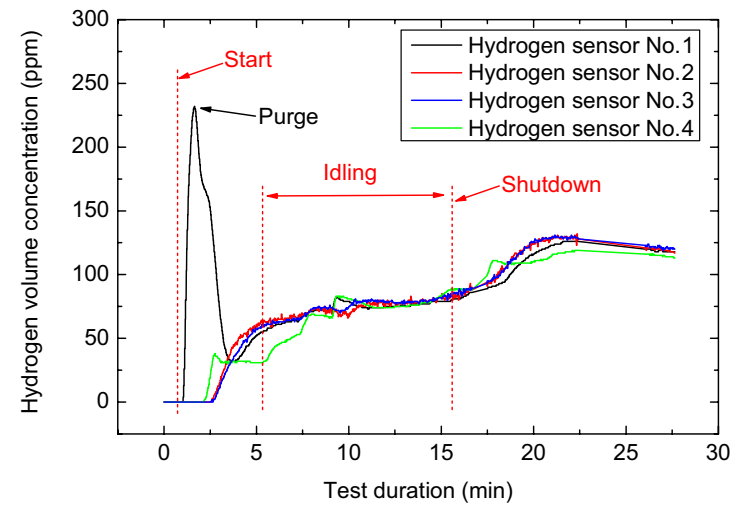

Fig. 7 In-chamber hydrogen concentration curve (vehicle B) under combined operating conditions was to say, the battery SOC of vehicle B was easier to reach a high condition, which would lead to the shutdown of the fuel cell engine. In comparison, a battery with higher capacity kept the fuel cell engine of vehicle A idling and charging the battery for 10 min continuously. Although the control strategies and operation sequence of vehicle $\mathrm{A}$ and vehicle B were different, it could be found that the purge process was the main reason of the increase in hydrogen concentration in the chamber. Consequently, the combined operating conditions, including start-up, idling, and shutdown, were recommended to measure the worst-case scenario.

The results of the two tests demonstrated that:

(1) The hydrogen emission of vehicle A was much higher than that of vehicle $\mathrm{B}$, indicating that the hydrogen safety of vehicle A in the garage was worse.

(2) The purge process after start-up caused the hydrogen concentration near the tail pipe of the vehicle to rise rapidly.

(3) During the idling process of the fuel cell engine, the hydrogen concentration in the surrounding environment of the vehicle was basically stable and did not rise with the idle duration. Therefore, the recommended idle duration in this investigation was $10 \mathrm{~min}$. This was sufficient to evaluate the hydrogen safety of the vehicle when it was idling in the garage without the need to increase the test duration.

(4) The highest hydrogen concentration in the chamber was caused by the purge process. Therefore, controlling the hydrogen emissions occurring due to the purge process is critical to the improvement of hydrogen safety of vehicles in a garage. First, improve the hydrogen utilization rate of a fuel cell engine by using components such as a hydrogen circulation pump and optimizing control strategy. Second, mix the appropriate amount of air into the FCV exhaust gas to dilute the hydrogen concentration by optimizing the pipeline design and control strategy of the air compressor.

(5) Hydrogen emission during vehicle operations in a garage was more likely to cause hydrogen safety risks than hydrogen leaks during parking.

\subsection{Recommendations for Standards and Regulations}

(1) Test equipment. In order to test and evaluate the hydrogen safety in a confined space for different FCVs, it is necessary to specify the details of the test chamber, including the internal dimensions, air change rate, details of mechanical ventilation (such as air velocity, fan diameter, exact position in the chamber), and details 
Table 5 Recommendations to the standards of FCV hydrogen safety in confined spaces

\begin{tabular}{lll}
\hline Items & Hydrogen leakage test under parking condition & Hydrogen emission test under operating condition \\
\hline Internal dimensions of test chamber & $\begin{array}{l}\text { The dimensions should be within } 1000 \mathrm{~mm} \text { larger than the vehicle in length or width, and } 500 \text { mm in } \\
\text { height above the highest point on the vehicle structure }\end{array}$ & $6 \mathrm{ACH}$ \\
Air change rate & $\leq 0.03 \mathrm{ACH}$ & Opened \\
Mechanical ventilation & Closed & 4 \\
Number of sensors & 4 & $0-10,000 \mathrm{ppm}$ \\
Hydrogen sensor test range & $0-10,000 \mathrm{ppm}$ & $1 \mathrm{ppm}$ \\
Hydrogen sensor resolution & $1 \mathrm{ppm}$ & $25 \pm 5^{\circ} \mathrm{C}$ \\
Test environment temperature & $25 \pm 5^{\circ} \mathrm{C}$ & $\mathrm{NWP}$ \\
Vehicle filling pressure & $\mathrm{NWP}$ & $12 \mathrm{~h}$ at $25 \pm 5^{\circ} \mathrm{C}$ \\
Vehicle soaking requirement & $12 \mathrm{~h} \mathrm{at} 25 \pm 5^{\circ} \mathrm{C}$ & $\mathrm{Start}-\mathrm{up}$, idling at least 10 min, shutdown \\
Test conditions & Parking & Duration including start-up, idling at least 10 min, \\
Test duration & $8 \mathrm{~h}$ & shutdown \\
Requirement of hydrogen concentra- & $\leq 10,000 \mathrm{ppm}$ & $\leq 10,000 \mathrm{ppm}$ \\
tion around the vehicle & $\geq 1 \mathrm{~Hz}$ & $\geq 1 \mathrm{~Hz}$ \\
Sampling frequency & &
\end{tabular}

of hydrogen sensor (such as accuracy and positions in the chamber).

(2) Test conditions. In order to guarantee the feasibility and repeatability of the test, it is suggested to specify the test preparation process (such as preparation procedure, vehicle conditions, ambient temperature, and soaking requirement), test process (such as test procedure, vehicle operation conditions, and test duration), and data acquisition requirement.

Based on this study, the recommendations to the standards of FCV hydrogen safety in confined spaces are summarized in Table 5.

\section{Conclusions}

This investigation systematically analyzed the current standards and regulations regarding hydrogen safety requirements for FCVs in confined spaces and identified various aspects that require further improvement based on existing test methods. Based on existing standards, the results of this investigation improved the test method for vehicle hydrogen safety in confined spaces and clarified the test equipment requirements, vehicle status requirements, test conditions, test procedures, and test durations, and established a complete set of test methods. Hydrogen leakage and emission tests were performed on two fuel cell passenger cars using the sealed chamber developed in this investigation. In order to improve the standards and regulations of FCV hydrogen safety in confined spaces, the recommendations, including test equipment and test conditions requirements, were presented based on the experimental investigations. The major conclusions could be summarized as follows:

(1) To meet the test requirements, explosion-proof, sealing, ventilation simulation, hydrogen concentration measurement, and emergency measures (such as audible and visual alarm and automatic emergency ventilation) should be considered in the design and development of a sealed chamber for hydrogen safety testing of FCVs.

(2) Hydrogen leakage tests were conducted on two vehicles with Type III and Type IV hydrogen storage tanks, respectively. The results showed that the hydrogen leaked from FCVs caused the hydrogen concentration in the chamber to increase linearly with time. After the vehicle was parked for $8 \mathrm{~h}$, the hydrogen concentration in the cabin was much lower than $1 \%$. As a consequence, the safety limit of $1 \%$ in GTR and SAE was not strict for the safety performance of FCV at present.

(3) Hydrogen emission test results showed that the peak hydrogen concentration in the chamber occurred during vehicle start-up purge, idle purge, or shutdown purge. The purge process was the most critical factors causing the increase in hydrogen concentration. If the control strategy of the purge process was not appropriate, it would cause the hydrogen concentration in the chamber to approach the safety limit of $1 \%$. Therefore, the hydrogen emission performance of vehicles in confined spaces should be paid much more attention.

Acknowledgements This work was supported by the Young Elite Scientists Sponsorship Program by CAST and China SAE, the National Key Research and Development Program of China (Grant No. 
2017YFB0103100) and Tianjin Municipal Science and Technology Commission Program (Grant No. 17ZXFWGX00040).

\section{Compliance with Ethical Standards}

Conflict of interest On behalf of all the authors, the corresponding author states that there is no conflict of interest.

Open Access This article is licensed under a Creative Commons Attribution 4.0 International License, which permits use, sharing, adaptation, distribution and reproduction in any medium or format, as long as you give appropriate credit to the original author(s) and the source, provide a link to the Creative Commons licence, and indicate if changes were made. The images or other third party material in this article are included in the article's Creative Commons licence, unless indicated otherwise in a credit line to the material. If material is not included in the article's Creative Commons licence and your intended use is not permitted by statutory regulation or exceeds the permitted use, you will need to obtain permission directly from the copyright holder. To view a copy of this licence, visit http://creativecommons.org/licenses/by/4.0/.

\section{References}

1. Manoharan, Y., Hosseini, S.E., Butler, B., et al.: Hydrogen fuel cell vehicles; current status and future prospect. Appl. Sci. 9(11), 2296 (2019)

2. Hajji, Y., Jouini, B., Bouteraa, M., et al.: Numerical study of hydrogen release accidents in a residential garage. Int. J. Hydrog. Energy. 40(31), 9747-9759 (2015)

3. Han, U., Oh, J., Lee, H.: Safety investigation of hydrogen charging platform package with CFD simulation. Int. J. Hydrog. Energy 43(29), 13687-13699 (2018)

4. Liu, W., Christopher, D.M.: Dispersion of hydrogen leaking from a hydrogen fuel cell vehicle. Int. J. Hydrog. Energy 40(46), 16673-16682 (2015)

5. Xie, H., Li, X., Christopher, D.M.: Emergency blower ventilation to disperse hydrogen leaking from a hydrogen-fueled vehicle. Int. J. Hydrog. Energy 40(25), 8230-8238 (2015)

6. Prasad, K.: High-pressure release and dispersion of hydrogen in a partially enclosed compartment: effect of natural and forced ventilation. Int. J. Hydrog. Energy 39(12), 6518-6532 (2014)

7. Olvera, A.H., Choudhuri, A.R.: Numerical simulation of hydrogen dispersion in the vicinity of a cubical building in stable stratified atmospheres. Int. J. Hydrog. Energy 31(15), 2356-2369 (2006)

8. Salva, J.A., Tapia, E., Iranzo, A., et al.: Safety study of a hydrogen leak in a fuel cell vehicle using computational fluid dynamics. Int. J. Hydrog. Energy 37(6), 5299-5306 (2012)

9. Sakamoto, J., Misono, H., Nakayama, J., et al.: Evaluation of safety measures of a hydrogen fueling station using physical modeling. Sustainability 10(11), 3846 (2018)

10. Molkov, V., Verbecke, F., Makarov, D.: LES of hydrogen-air deflagrations in a 78.5-m tunnel. Combust. Sci. Technol. 180(5), 796-808 (2008)

11. Middha, P., Hansen, O.R.: CFD simulation study to investigate the risk from hydrogen vehicles in tunnels. Int. J. Hydrog. Energy 34(14), 5875-5886 (2009)
12. Houf, W.G., Evans, G.H., Merilo, E., et al.: Releases from hydrogen fuel-cell vehicles in tunnels. Int. J. Hydrog. Energy 37(1), 715-719 (2012)

13. Tolias, I.C., Venetsanos, A.G., Markatos, N., et al.: CFD modeling of hydrogen deflagration in a tunnel. Int. J. Hydrog. Energy 39(35), 20538-20546 (2014)

14. Bie, H.Y., Hao, Z.R.: Simulation analysis on the risk of hydrogen releases and combustion in subsea tunnels. Int. J. Hydrog. Energy 42(11), 7617-7624 (2017)

15. Pitts, W.M., Yang, J.C., Blais, M., et al.: Dispersion and burning behavior of hydrogen released in a full-scale residential garage in the presence and absence of conventional automobiles. Int. J. Hydrog. Energy 37, 17457-17469 (2012)

16. Merilo, E.G., Groethe, M.A., Colton, J.D., et al.: Experimental study of hydrogen release accidents in a vehicle garage. Int. J. Hydrog. Energy 36(3), 2436-2444 (2011)

17. Molkov, V., Shentsov, V.: Numerical and physical requirements to simulation of gas release and dispersion in an enclosure with one vent. Int. J. Hydrog. Energy 39(25), 13328-13345 (2014)

18. Koutsourakis, N., Venetsanos, A.G., Bartzis, J.G.: LES modelling of hydrogen release and accumulation within a non-ventilated ambient pressure garage using the ADREA-HF CFD code. Int. J. Hydrog. Energy 37(22), 17426-17435 (2012)

19. Choi, J., Hur, N., Kang, S., et al.: A CFD simulation of hydrogen dispersion for the hydrogen leakage from a fuel cell vehicle in an underground parking garage. Int. J. Hydrog. Energy 38(19), 8084-8091 (2013)

20. Venetsanos, A.G., Papanikolaou, E., Delichatsios, M., et al.: An inter-comparison exercise on the capabilities of CFD models to predict the short and long term distribution and mixing of hydrogen in a garage. Int. J. Hydrog. Energy 34(14), 5912-5923 (2009)

21. Giannissi, S.G., Tolias, I.C., Venetsanos, A.G.: Mitigation of buoyant gas releases in single-vented enclosure exposed to wind: removing the disrupting wind effect. Int. J. Hydrog. Energy 41(6), 4060-4071 (2016)

22. Papanikolaou, E.A., Venetsanos, A.G., Heitsch, M., et al.: HySafe SBEP-V20: numerical studies of release experiments inside a naturally ventilated residential garage. Int. J. Hydrog. Energy 35(10), 4747-4757 (2010)

23. Tolias, I.C., Giannissi, S.G., Venetsanos, A.G., et al.: Best practice guidelines in numerical simulations and CFD benchmarking for hydrogen safety applications. Int. J. Hydrog. Energy 44(17), 9050-9062 (2019)

24. Baraldi, D., Melideo, D., Kotchourko, A., et al.: Development of a model evaluation protocol for CFD analysis of hydrogen safety issues the SUSANA project. Int. J. Hydrog. Energy 42(11SI), 7633-7643 (2017)

25. Adams, P., Bengaouer, A., Cariteau, B., et al.: Allowable hydrogen permeation rate from road vehicles. Int. J. Hydrog. Energy 36(3), 2742-2749 (2011)

26. Brennan, S., Molkov, V.: Safety assessment of unignited hydrogen discharge from onboard storage in garages with low levels of natural ventilation. Int. J. Hydrog. Energy 38(19), 8159-8166 (2013)

27. United Nations. Global Technical Regulation No. 13 Global Technical Regulation on Hydrogen and Fuel Cell Vehicles, pp. 22-41 (2013)

28. Society of Automotive Engineers. J 2578 Recommended Practice for General Fuel Cell Vehicle Safety, pp. 54-60 (2014) 